\title{
FIRE RESISTANCE PERFORMANCE ANALYSIS OF HIGH-STRENGTH STEEL Q550 COLUMNS UNDER AXIAL COMPRESSION
}

\author{
Sheng-Gang Fan ${ }^{1 . *}$, Shuai $\mathrm{Li}^{2}$, Bing-Bing $\mathrm{He}^{3}$, Lian-Lian $\mathrm{Jia}^{4}$, and Run-Min Ding ${ }^{5}$ \\ Key Laboratory of Concrete and Prestressed Concrete Structures of Ministry of Education, Southeast University, \\ School of Civil Engineering, Southeast University, Nanjing 210096, China, \\ * (Corresponding author: E-mail: 101010393@seu.edu.cn)
}

\section{A B S T R A C T}

With the improvement in steel production technology, high-strength steel, as a building material, has become a new current in civil engineering. To reveal the mechanical behavior of axially compressed high-strength steel Q550 (a nominal yield strength $f_{y} \geq 550 \mathrm{MPa}$ ) columns without axial constraint at elevated temperatures, the finite element method was used to establish several transient analysis models with the software ABAQUS. The accuracy of the finite element model was verified by comparison with the results of prior experiments. To investigate the mechanical behavior and failure mechanism of high-strength steel Q550 columns in fire, the fire resistance of Q550 columns was numerically simulated and analyzed based on effective finite element models. The effects of the parameters on the fire resistance of high-strength steel Q550 column with a rectangular hollow section under axial compression were studied with an emphasis on the load ratio, initial imperfection amplitude, slenderness ratio and sectional dimensions. The results indicate that the load ratio is the main factor affecting the fire resistance performance of high-strength steel Q550 columns.

\section{A R T I C LE H I S T O RY}

$\begin{array}{ll}\text { Received: } & \text { 04 June } 2018 \\ \text { Revised: } & \text { 09 September } 2018 \\ \text { Accepted: } & \text { 15 September } 2018\end{array}$

\section{K E Y W O R D S}

High-strength steel Q550;

Axial compression;

Fire resistance performance;

Critical temperature

\section{Introduction}

As a special building steel, high-strength steel is produced by micro alloying and thermomechanical controlled rolling technology (Shi et al [1]) and has good ductility, processing properties and high yield strength (a nominal yield strength $f_{y} \geq 460 \mathrm{MPa}$ ). The use of high-strength steel not only decreases the section dimensions, steel consumption and hoisting difficulty, but also increases the usable area and then reduces the whole life cycle cost for the buildings. At present, high-strength steel has been applied to plenty of structures in China, such as the New CCTV Building and the National Stadium, with good results (Fan et al [2]; Chen [3]). High-strength steel Q460E/Z35 was used in the National Stadium to decrease the wall thickness and welding working load, which facilitated joint construction. In the New CCTV Building, the use of materials was minimized with the adoption of high-strength steel Q460D and Q460E in columns and braces.

Fire occasionally affects buildings. Fire safety cost in buildings remains at a high level in China, which means that fire safety in buildings in China is rigorous. From 2003 to 2012, there were 180 thousand fires per year in China with 1698 fire deaths, 1426 fire injuries and the direct economic losses of 1.626 billion Yuan ( $\mathrm{Fu} \mathrm{[4]).} \mathrm{In} \mathrm{2012,} \mathrm{there} \mathrm{were} 152$ thousand fires in China with 1028 fire deaths, 575 fire injuries and the direct economic loss of 2.18 billion Yuan [5]. In 2013, the number of fires almost tripled to 388 thousand in China and led to 2113 fire deaths, 1637 fire injuries and the direct economic losses of 4.85 billion Yuan [6]. In 2014, there were 395 thousand fires in China with 1815 fire deaths, 1513 fire injuries and the direct economic losses of 4.6 billion Yuan [7]. In 2015, the amount of fires decreased a little to 338 thousand in China, resulting in 1742 fire deaths, 1112 fire injuries and the direct economic losses of 3.95 billion Yuan [8]. Therefore, the harm caused by fire to human life should not be underestimated.

So far, many researches on structural fire resistance have been conducted. Fan et al. [9] carried out theoretical analysis and finite element analysis of the fire temperature fields on large space steel structures. Fan et al. [10] conducted researches on the membrane effect of steel sheet-concrete composite slabs with special shape under fire. In order to facilitate the direct analysis and second-order inelastic analysis of steel structures, Du et al. [11] proposed a new flexibility-based beam-column element with member initial imperfection. However, there are few researches on the fire resistance of high-strength steel at present. High-strength steel (HSS) has several advantages, while the strength and stiffness are greatly reduced at high temperatures just as ordinary structural steel, resulting in the poor fire resistance. The Chinese Technical Code for fire safety of ordinary steel structures in buildings (CECS200:2006) [12], the American Code (AISC 360-2010) [13] and the European Code (EN 1993-1-2) [14] all proposed methods on the fire-resistant design of steel structures based on calculations and provided recommended values for the material reduction factors at elevated temperatures. But the fire-resistant design methods for ordinary steel columns and high-strength steel columns are completely different because the mechanical properties of ordinary steel and high-strength steel vary at high temperatures. So the current design method for high-strength steel is not very applicable. Firstly, the smelting of high-strength steel adopts micro alloying technology, resulting in high-strength steel with some special metal elements such as $\mathrm{V}, \mathrm{Nb}, \mathrm{Mo}, \mathrm{Cr}$, and so on, and these elements are in great request for fire-resistant steel (Liu et al [15]). Ordinary steel does not possess these metal elements, and such that the influence on the fire resistance of HSS requires further research. Secondly, with both high ultimate strength and yield strength, HSS has a high yield ratio, a short yield plateau or even no yield plateau and a short ultimate tensile strain (Shi [16]; Ban et al [17]), differing from ordinary steel.

Several studies exist on the fire resistant design of high-strength steel in China. Liu et al. [15] found obvious differences by comparing the fire resistance of high-strength $\mathrm{H}$-section steel columns(HS-HC) with the ordinary steel $\mathrm{H}$-section columns(OS-HC) under axial compression at elevated temperatures. Wang [18] investigated the critical temperature and stability factor of high-strength steel columns and ordinary steel columns under axial compression at elevated temperatures, and the results showed that the critical temperature and stability factor of ordinary steel were not suitable for high-strength steel. Ge [19] carried out fire test and numerical simulation and analysis of axially compressed HS-HC with axial constraints at high temperatures and proposed key factors influencing the fire resistance of HS-HC under axial compression. Chen [20] conducted the finite element analysis on high-strength steel columns with an $\mathrm{H}$ section(HS-HC) and a rectangular hollow section(HS-HSS) under axial compression, and then compared the results with the design codes of American, European, the direct strength method (DSM) and Australian Standards (AS 4100: 1998) . Conclusions were made that the American and European design codes and the DSM are all conservative while the Australian code is optimistic for both HS-HC and HS-HSS at elevated temperatures.

\section{Material tests}

\subsection{Material tests of high-strength steel Q550 at room temperature}

Shi [16] conducted material tests on five Q550 specimens at room temperature, which were cut from the same original 5.8-mm-thick hot rolling plate. The test results showed that the ultimate strength and yield strength of the steel plate in the orthogonal direction were higher than those in the rolling direction. Qiu et al. [21-22] measured the elongation ratio, ultimate strength and yield strength of 12-mm-thick samples with high-strength Q550 and Q550GJ steel. Xue [23] also performed material tests on 12-mm-thick samples of high-strength steel Q550GJ at room temperature. The test results are given in Table 1. 
Table 1

Test results of high-strength steel Q550 at room temperature

\begin{tabular}{|c|c|c|c|c|c|c|c|}
\hline $\begin{array}{c}\text { Steel } \\
\text { Grade }\end{array}$ & Direction & $\mathrm{t} / \mathrm{mm}$ & $\begin{array}{c}\text { fy } \\
/ \mathrm{MPa}\end{array}$ & $\begin{array}{c}\mathrm{fu} \\
/ \mathrm{MPa}\end{array}$ & $\begin{array}{c}\mathrm{E} \\
/ \mathrm{GPa} \\
\end{array}$ & $\delta / \%$ & fy / fu \\
\hline \multirow{7}{*}{$\begin{array}{c}\text { Shi [16] } \\
\text { Q550 }\end{array}$} & \multirow{4}{*}{ F } & 5.8 & 741 & 800 & 204 & 22.1 & 0.93 \\
\hline & & & 745 & 796 & 213 & 21.6 & 0.94 \\
\hline & & Ave & 743 & 798 & 208 & 21.9 & 0.93 \\
\hline & & & 706 & 771 & 217 & 21.8 & 0.92 \\
\hline & \multirow{3}{*}{11} & 5.8 & 701 & 772 & 201 & 22.5 & 0.90 \\
\hline & & & 709 & 778 & 205 & 21.7 & 0.91 \\
\hline & & Ave & 706 & 774 & 208 & 22.0 & 0.91 \\
\hline Qiu [21] & \multirow{3}{*}{ I } & \multirow{3}{*}{12} & 649 & 719 & I & 20.0 & 0.90 \\
\hline \multirow[t]{2}{*}{ Q550 } & & & 666 & 738 & I & 25.0 & 0.90 \\
\hline & & & 631 & 787 & I & 17.0 & 0.80 \\
\hline Qiu [22] & \multirow{4}{*}{ I } & 12 & 624 & 801 & l & 18.0 & 0.78 \\
\hline Q550GJ & & & 616 & 801 & 1 & 17.0 & 0.77 \\
\hline & & Ave & 624 & 796 & l & 17.3 & 0.78 \\
\hline \multirow{4}{*}{ Xue [23] Q550GJ } & & & 633 & 746 & 1 & 22.0 & 0.85 \\
\hline & \multirow{3}{*}{ I } & 12 & 626 & 770 & l & 19.2 & 0.81 \\
\hline & & & 645 & 757 & I & 21.0 & 0.85 \\
\hline & & Ave & 635 & 758 & I & 20.8 & 0.84 \\
\hline
\end{tabular}

Note: Dir is the abbreviation of cutting direction of the test specimens. The symbol - means that the specimens are perpendicular to the rolling direction, and symbol $\mid$ means the specimens are parallel to the rolling direction. Ave is the abbreviation of 'Average' and represents the average value of test results.

From Table 1, Q550GJ has a lower yield strength and a higher ultimate strength compared with Q550 and such that its yield ratio is less than 0.85 , which satisfies the limit of the Chinese design code. The yield strength and ultimate strength of high-strength steel Q550 are close to each other, and the yield ratio is very high. Similar to ordinary steel, the strength of Q550 decreases with an increase in thickness.

\subsection{Material tests of $Q 550$ at elevated temperatures}

At present, material test data on high-strength steel Q550 at high temperatures are limited. However, some scholars researched cold-formed high-strength steel G550 at high temperatures.

Chen [20] conducted material tests on 1-mm-thick samples of cold-formed high-strength steel Q550 at high temperatures with a tensile strain rate 0.006 min-1. Based on the experiments, the reduction formulas of the ultimate tensile strain, elastic modulus, ultimate strength and yield strength were proposed as well as the constitutive model for cold-formed high strength G550 steel at high temperatures.

Chen and Ye [24-25] also did a series of material tests of 1-mm-thick cold-formed high-strength steel Q550 at high temperatures, including a standard tensile test of flat specimen, a standard tensile test of corner specimen, a thermal expansion test, a thermal steady test of flat specimen, a thermal transient test of flat specimen and a steady test of corner specimen. According to the experiment results, the reduction formulas of the ultimate tensile strain, elastic modulus, ultimate strength, and yield strength were proposed respectively at elevated temperatures. The constitutive model was also provided based on classical Ramberg-Osgood formula

However, the mechanical properties of cold-formed high-strength steel decreased rapidly with increasing temperature due to the gradual disappearance of the mechanical properties of cold-formed steel with small thickness at elevated temperatures (Chen and Ye [25]).

Some scholars have measured the mechanical properties of other grades of high-strength steel at high temperatures. Liu [26], Schneider and Lange [27] and Chiew et al. [28] provided the material properties of the different classes of high-strength steel at high temperatures. Through the steady and transient test methods, Qiang et al. [29-30] obtained the elastic modulus, yield strength and ultimate strength of the S460N and S690 steel samples at high temperatures. The results were compared with those of the European Code (EN 1993-1-2), the American Code (AISC 360-2010) and Australian Standards (AS 4100: 1998), and the fitting formulas of the material properties were proposed. The results showed that the American Code (AISC 360-2010) and Australian Standards (AS 4100: 1998) were optimistic in some temperature ranges. Chen [20] carried out transient and steady tests on Bisplate80, and presented the fitting formulas for the reduction factor and constitutive model.

As shown in Fig. 1 (a) and (b), the reduction factors for the material properties of high-strength steel at high temperatures differ greatly among varied grades and test methods (S, T, F and C refer to the Steady, Transient, Flat, and Corner tests, respectively). Conclusions can be drawn as follows. Firstly, when the temperature is more than $300^{\circ} \mathrm{C}$, the reduction coefficients of the yield strength and elastic modulus of cold-formed G550 steel decrease rapidly. As reported in the literature (Chen and Ye [25]), as the temperature increased, the mechanical properties of cold-formed high-strength steel decreased gradually. Secondly, the reduction factors of the yield strength and elastic modulus vary significantly within different grades of high-strength steel at elevated temperatures, especially at $600^{\circ} \mathrm{C}$. Finally, the reduction factors for the material properties of carbon steel at high temperatures proposed by the European Code (EN 1993-1-2) [14], the Chinese code (CECS200:2006) [12] and the American Code (AISC 360-2010) [13] are not applicable to high-strength steel.

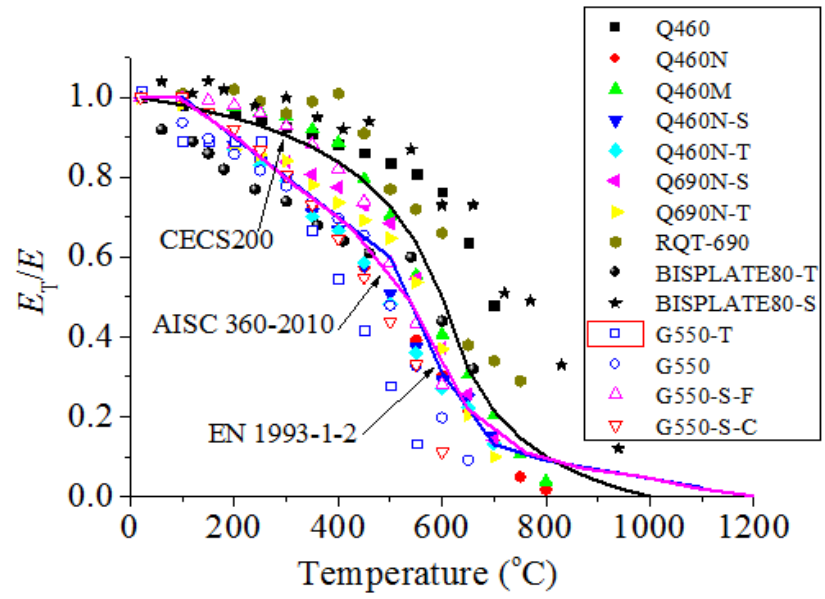

(a) Elastic modulus

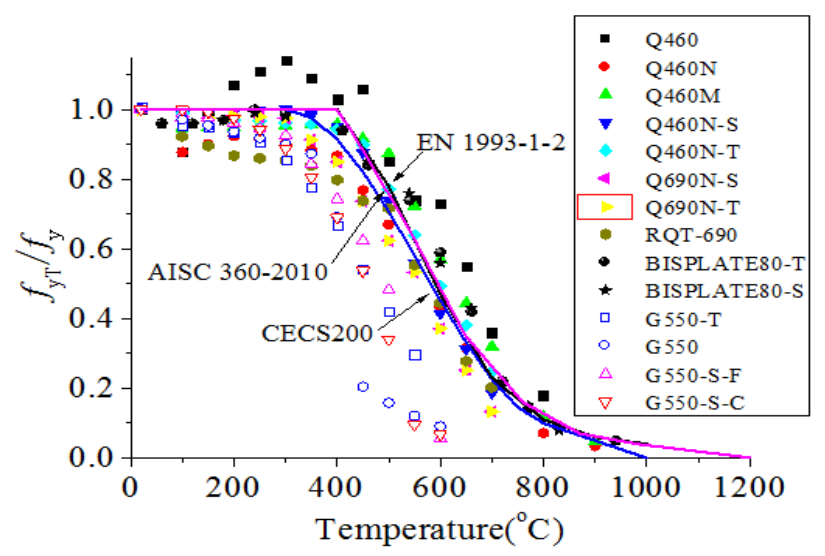

(b)Yield strength

Fig. 1 Reduction factors of hss at elevated temperatures

\subsection{Constitutive model}

Ban et al. [31] and Shi et al. [32] proposed two-stage constitutive models for high-strength steel with and without yield plateaus and the accuracy of the two models was proved. According to the material test results (Shi [16]), high-strength steel Q550 exhibited a short yield plateau, and such that the two-stage constitutive model with a yield plateau was adopted in this paper. 
The constitutive model is given in Eq. (1) and Fig. 2.

$\sigma=\left\{\begin{array}{cl}E \varepsilon & , 0 \leq \varepsilon \leq \varepsilon_{y} \\ f_{y} & , \varepsilon_{y} \leq \varepsilon \leq \varepsilon_{s t} \\ f_{y}+\left(\varepsilon-\varepsilon_{s t}\right)\left(f_{u}-f_{y}\right) /\left(\varepsilon_{u}-\varepsilon_{s t}\right) & , \varepsilon_{s t} \leq \varepsilon \leq \varepsilon_{u}\end{array}\right.$

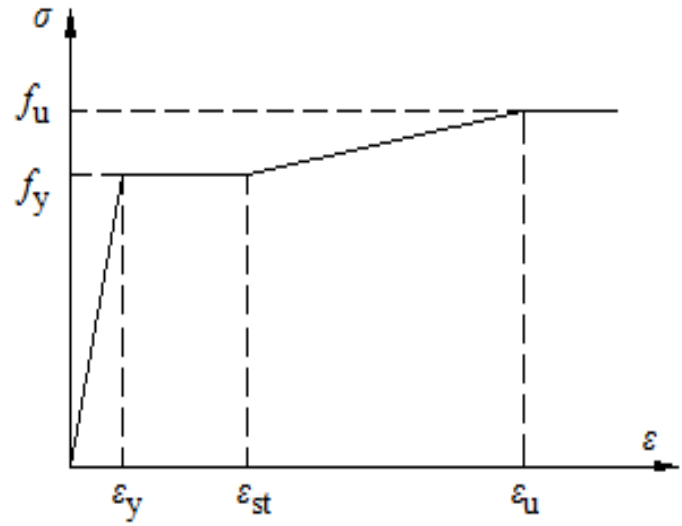

Fig. 2 Constitutive model with a yield plateau

The material data of high-strength steel Q550 in rolling direction from Shi [16] were adopted in this paper, and the reduction factors at elevated temperatures proposed by Qiang et al. [30] were used in the formula as shown in Fig. 3.

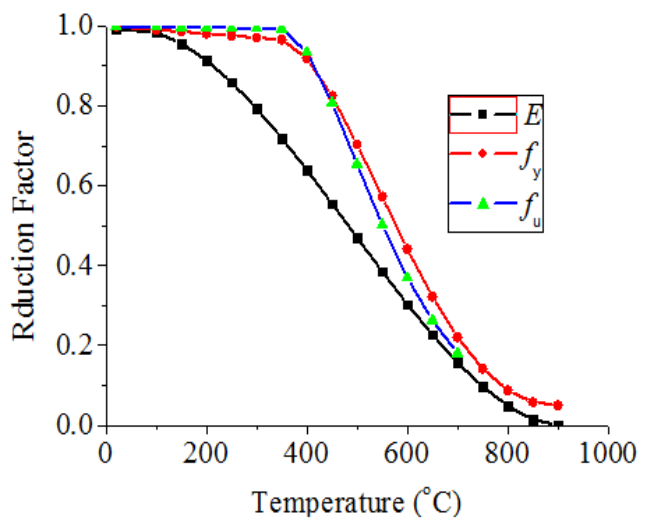

Fig. 3 Reduction factors

\section{Analysis methods and models}

\subsection{Analysis methods}

In real fire conditions, steel columns are generally subjected to both temperature effects and external loads and the thermomechanical coupling method is adopted for analysis. There are two main types of thermomechanical coupling: the complete thermomechanical coupling analysis and the subsequent thermomechanical coupling analysis and the latter type was adopted in this paper. The results of the temperature field are not significantly influenced by the results of the stress analysis while the results of stress analysis are significantly influenced by the results of the temperature field.

The subsequent thermomechanical coupling analyses includes transient analysis and steady-state analysis. In the steady-state analysis, the temperature field keeps unchanged and the load is applied to the columns gradually until columns fail. On the contrary, in the transient analysis, external load remains the same and the temperature increases to a certain rate until the failure of columns. When a real fire occurs, the steel column always bears a certain load with increasing temperature gradually. The material properties of steel decrease with increasing temperature and finally the steel columns lose capacity or stability. Therefore, the transient analysis is more in line with the actual situation. In this paper, the transient analysis method was adopted to analyze the fire resistance of high-strength steel Q550 column with a rectangular hollow section under axial compression.

\subsection{Analysis models}

The transient analysis model includes four submodels: the linear elastic buckling analysis model, the bearing capacity analysis model, the fire resistance analysis model and the heat transfer analysis model. The bearing capacity analysis model and the linear elastic buckling analysis model are used to calculate the ultimate bearing capacity of the steel column at room temperature, and the temperature field of the steel column can be simulated by the heat transfer analysis model. The fire resistance analysis model coupling the temperature and stress field is for analysis of the material properties of steel columns at high temperatures.

\section{Analysis methods and models}

\subsection{Establishment of the finite element model}

In this paper, the finite element software ABAQUS was adopted to establish the model. The four-node heat transfer quadrilateral shell element DS4 in ABAQUS was applied to the heat transfer analysis model. The rest analysis models adopted the S4R four-node shell element. The S4R element in ABAQUS is a generic shell element type with outstanding adaptability, which could be used in the simulation of thick and thin shell problems.

(1) Linear buckling analysis model. The steel has a density of $78.50 \mathrm{kN} / \mathrm{m} 3$, with a Poisson ratio 0.3 and elastic modulus $2.076 \times 1011 \mathrm{~Pa}$. To simplify the boundary conditions of column, the cross section at each column end was coupled to a reference point as shown in Fig. 4(a). The column is simply supported and the displacements U1, U2, U3 and rotation UR2, UR3 are restrained at one end, while the other end is restrained at the freedom of U1, U2, UR2 and UR3, as shown in Fig. 4(b). A unit force was applied at the column end and a linear buckling analysis step was performed for the buckling mode of the steel column

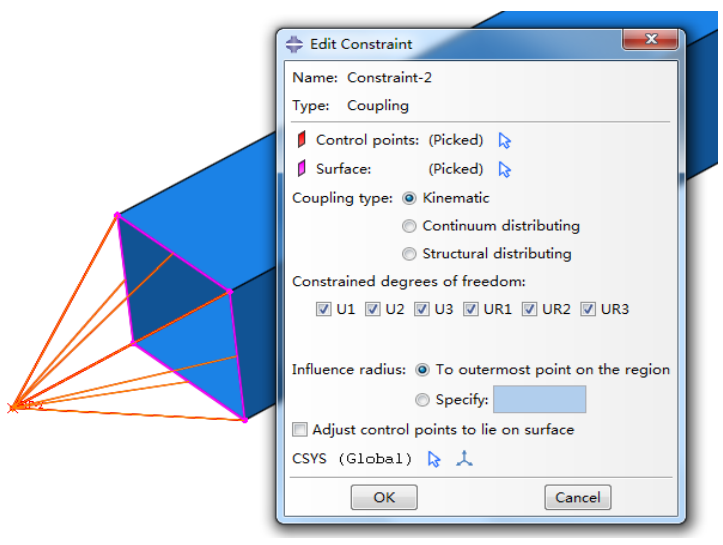

(a) Coupling setting

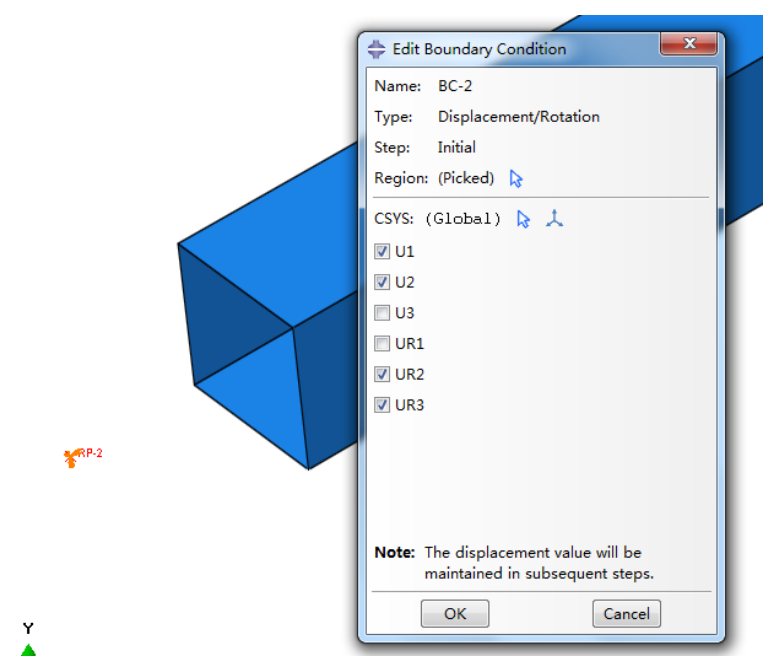

(b) End condition setting

Fig. 4 Boundary condition setting

(2) Bearing capacity analysis model. The arc length method was adopted 
with elasto-plastic material and the unit load at column end was replaced with a displacement of $-0.1 \mathrm{~m}$. The initial imperfection and residual stress were introduced by keywords, and the residual stress proposed by Shi [16] was illustrated in the model shown in Fig. 5 (a) and (b).

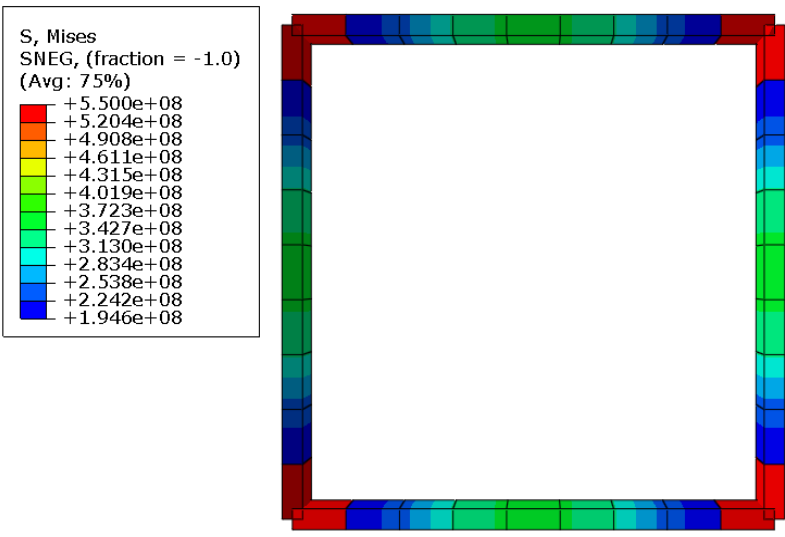

(a) Miss stress distribution

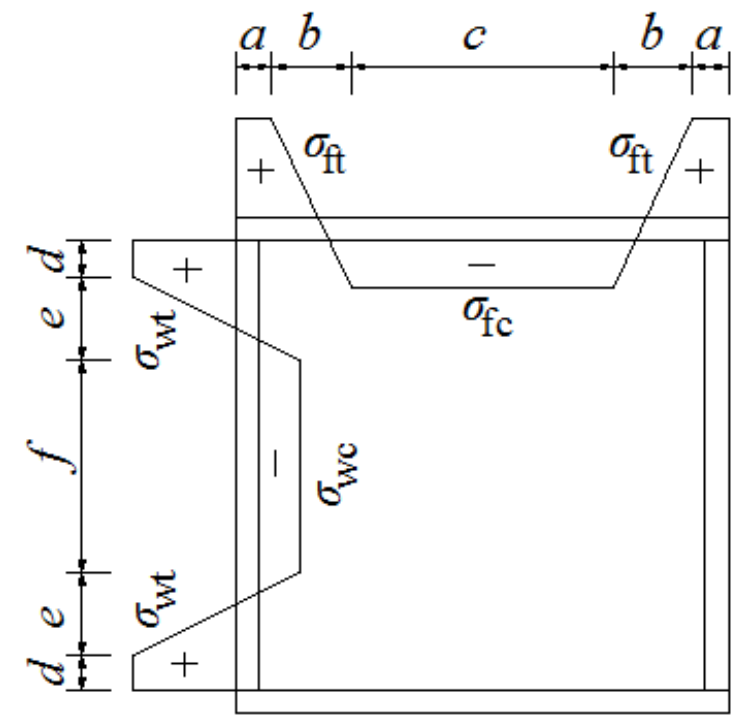

(b) Residual stress distribution

Fig. 5 Residual stress distribution model

(3) Heat transfer analysis model. The thermal parameters of the material were introduced on the basis of the linear buckling analysis model. Considering that the composition of the steel had little effect on thermal parameters and the current research results of high-strength steel were still limited, the parameters of ordinary steel proposed by Wang and Li [33] and the relevant regulations of carbon steel from the European Code (EN 1993-1-2) [14] were adopted in this paper. To simulate the test specimens exposed to fire with four sides, the heat transfer analysis step was established in this paper.

(4) Fire resistance analysis model. Based on the bearing capacity analysis model, mechanical parameters and the expansion coefficient of the high-strength steel material were introduced. The load specified under certain load ratio was applied at the column end, and the temperature in the heat transfer model was included to create the predefined field.

\subsection{Verification of the bearing capacity model}

To verify the accuracy and efficiency of bearing capacity model in section 4.1, the finite element model was established by the parameters of

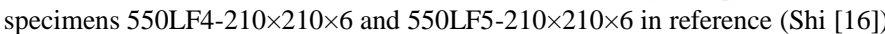
and the model results were analyzed and checked against the test results. As shown in Table 2 and Table 3, the geometric dimensions, test results and numerical simulation results of the two specimens are given. The failure mode of the specimen exhibits an overall bending failure in a certain direction. Due to the limitation of length, only the failure mode and load-displacement curve of specimen 550LF4 are given in Fig. 6 and Fig. 7.

Table 2

Parameters of the models

\begin{tabular}{cccc}
\hline \multirow{2}{*}{ Specimens } & $\mathrm{L} / \mathrm{mm}$ & \multicolumn{2}{c}{$\mathrm{e}_{0} / \mathrm{mm}$} \\
\cline { 3 - 4 } & & overall & local \\
\hline 550 LF4 & 3292.6 & 4.63 & 0.494 \\
550 LF5 & 3842.2 & 1.34 & 0.494 \\
\hline
\end{tabular}

Note: the section size of specimen 550LF4 is $209.7 \times 211.5 \times 5.8$ (height $\times$ width $\times$ thickness); the section size of specimen 550LF5 is $210.8 \times 211.4 \times 5.8$; 'overall' refers to the amplitude of overall imperfection; 'local' refers to the amplitude of local imperfection.

Table 3

Results of the models

\begin{tabular}{cccc}
\hline \multirow{2}{*}{ Specimens } & \multicolumn{2}{c}{ Bearing Capacity $/ \mathrm{kN}$} & \multirow{2}{*}{ Ffem//Fu } \\
\cline { 2 - 3 } & $\mathrm{Fu}$ & $\mathrm{Ffem}$ & \\
\hline $550 \mathrm{LF} 4$ & 2110.0 & 2260.8 & 1.07 \\
550 LF5 & 2266.7 & 2310.7 & 1.02 \\
\hline
\end{tabular}

Note: $\mathrm{Fu}_{\mathrm{u}}$ is the bearing capacity given by test results; $\mathrm{F}_{\mathrm{fem}}$ is the bearing capacity

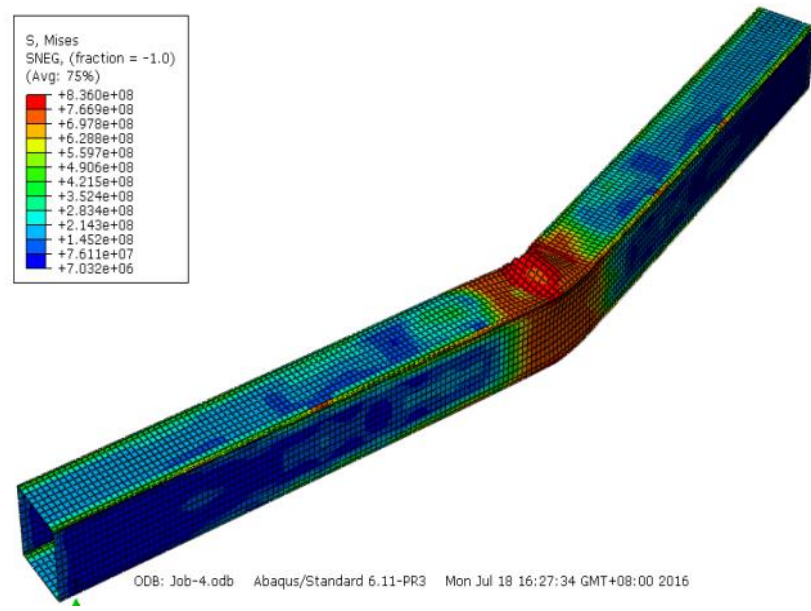

Fig. 6 Failure mode of LF4

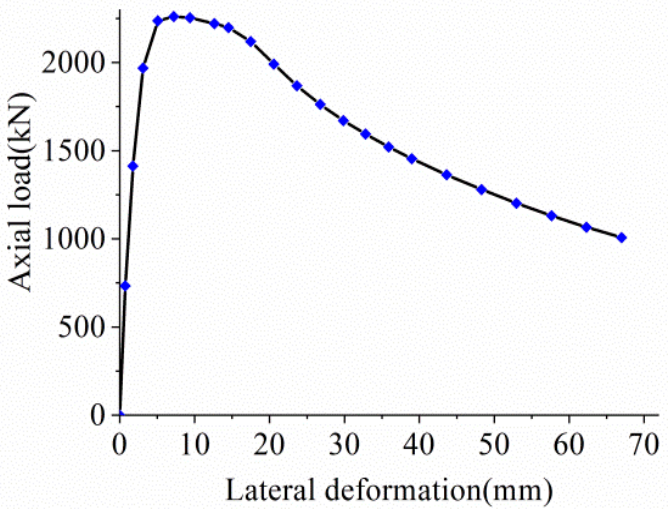

Fig. 7 Load-displacement curve of LF4

The bearing capacity $(2110 \mathrm{kN})$ of specimen 550LF4 given by finite element analysis is very close to that $(2066.8 \mathrm{kN})$ of the test result in the literature (Shi [16]) with a relative error $-2.0 \%$. The bearing capacity calculated by the model in this paper was $2260.8 \mathrm{kN}$ with a relative error $+7.0 \%$. In previous studies, the testing bearing capacity of specimen 550LF5 was $2266.7 \mathrm{kN}$, agreed well with the finite element analysis result $2108.1 \mathrm{kN}$ with a relative error $-7.0 \%$. The bearing capacity in this paper $2310.7 \mathrm{kN}$ possessed relative error $+2.0 \%$. The results indicate that the analysis model of the bearing capacity at room temperature in this paper has higher accuracy. 
In the reference (Liu [26]), the critical temperature of the high-strength steel Q460 column with the HW $200 \times 200 \times 8 \times 12$ section was solved by three methods (the critical stress, inverse calculation and finite element method) on the basis of mechanical property tests at high temperatures. The parameters from the reference (Liu [26]) were applied to establish the fire-resistance analysis model of the steel column under two different slenderness ratios and seven load ratios, as shown in Table 4.

Table 4.

Results of the fire-resistance analysis model

\begin{tabular}{cccccccc}
\hline \multicolumn{7}{c}{$\lambda=50$} \\
\hline $\mathrm{n}$ & 0.3 & 0.4 & 0.5 & 0.6 & 0.7 & 0.8 & 0.9 \\
$\mathrm{Tcr}$ & 767 & 730 & 692 & 653 & 614 & 575 & 535 \\
$\mathrm{Tfe}$ & 768 & 731 & 700 & 669 & 638 & 603 & 570 \\
$\mathrm{Tfe} / \mathrm{Tcr}$ & 1.00 & 1.00 & 1.01 & 1.02 & 1.04 & 1.05 & 1.07 \\
\hline & & & $\lambda=130$ & & & \\
\hline $\mathrm{n}$ & 0.3 & 0.4 & 0.5 & 0.6 & 0.7 & 0.8 & 0.9 \\
$\mathrm{Tcr}$ & 809 & 788 & 760 & 725 & 681 & 623 & 549 \\
$\mathrm{Tfe}$ & 829 & 793 & 762 & 715 & 680 & 619 & 519 \\
$\mathrm{Tfe} / \mathrm{Tcr}$ & 1.02 & 1.01 & 1.00 & 0.99 & 1.00 & 0.99 & 0.94 \\
\hline
\end{tabular}

Note: $\lambda$ is the slenderness ratio; $\mathrm{n}$ is the load ratio; Tcr is the critical temperature in the reference (Liu [26]); Tfe is the critical temperature calculated by the model in this paper.

It can be seen from Table 4 that the relative error of the model is small (less than $5 \%$ ) when the load ratio $\mathrm{n}$ ranges from 0.1 to 0.8 under different slenderness ratios while slightly larger $(6 \%$ and $7 \%)$ when $\mathrm{n}$ is 0.9 . The data show that the fire-resistance analysis model of the steel column established in this paper is able to simulate the mechanical behavior of the steel column at high temperatures with high accuracy.

\section{PARAMETRIC ANALYSES OF THE FIRE RESISTANCE}

With the finite element software ABAQUS, parametric analysis was conducted on high-strength steel Q550 columns with square hollow section under axial compression. In the finite element model, the temperature rose following the standard temperature-time relationship ISO-834. The effects of slenderness ratio, load ratio and initial imperfection amplitude on the fire resistance of axially compressed high-strength steel Q550 columns with square hollow sections were analyzed. Three section sizes were considered: $80 \times 80 \times 4,100 \times 100 \times 4$ and $120 \times 120 \times 5$ and the initial load ratio was set as 0.3 in the analysis. The initial imperfection amplitude L/1000 and 3300mm-length specimen as well as a $110-\mathrm{mm}$ pin hinge support at each column end were included.

\subsection{Load Ratio}

To investigate the effects of the load ratio on the fire resistance of high-strength steel Q550 columns with square hollow sections under axial compression, the load ratios $0.2,0.3,0.4,0.5,0.6,0.7,0.8$ and 0.9 were contained. The initial imperfection amplitude and component length were kept constant with the value of $\mathrm{L} / 1000$ and $3300 \mathrm{~mm}$ respectively. Due to the limitation of space, only the axial displacement-load curves of the $100 \times 100 \times 4$ specimen are given in Fig. 8. The curves of maximum axial displacement and critical temperature of specimens are illustrated in Fig. 9 (a) and (b).

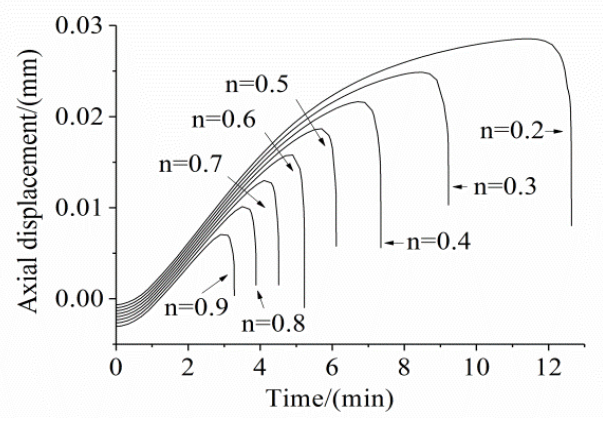

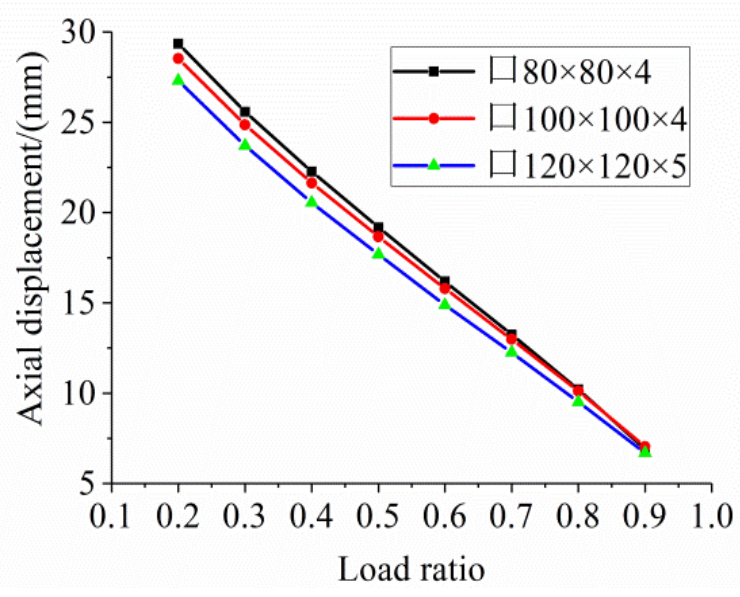

(a) Maximum axial displacement-load ratio curves

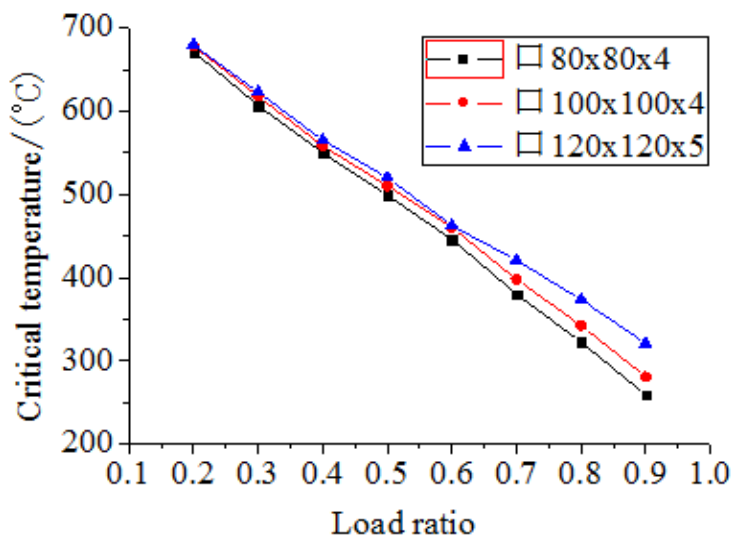

(b) Critical temperature - load ratio curves

Fig. 9 Effects of the load ratio on the fire resistance of the specimen

Fig. 8 demonstrates the axial displacement-time curves of high-strength steel Q550 columns with a square hollow section of $100 \times 100 \times 4$ at different load ratios. The curve can be divided into three stages: (1) the loading stage, when the specimens are loaded at room temperature, resulting in small axial displacements; (2) the temperature expansion stage, when the specimens elongate with the increase of temperature, the mechanical properties decrease at the same time. The specimen gradually yields and the curve tends to be horizontal. The temperature at the time specimen fails characterized by the axial displacement reaching the maximum value is defined as the critical temperature. (3) In the post-failure stage, the curve decreases rapidly after the destruction point and the ductility is relatively poor after failure.

As shown in Fig. 9 (a) and (b): (1) The load ratio greatly influences the critical temperature and axial displacement. The critical temperature and the maximum axial displacement are almost negatively correlated with the load ratio; (2) When the load ratio exceeds 0.6 , the section size of the specimen has a greater impact than other load ratios on the critical temperature. The critical temperature rises as the section size increases with constant specimen length.

\subsection{Initial Imperfection Amplitude}

To Fig. out the effects of the initial imperfection amplitude on the fire resistance of high-strength steel Q550 columns with square hollow section under axial compression, the length of components and the load ratio were kept constant at $3300 \mathrm{~mm}$ and 0.3 respectively, and the initial imperfection amplitudes included L/1000, L/500, L/300 and L/100 separately. Only the axial displacement-load curves of the $100 \times 100 \times 4$ specimen are given in Fig. 10 due to limitation of space.The relationship between maximum axial displacement and critical temperature of specimens are shown in Fig. 11 (a) and (b). 


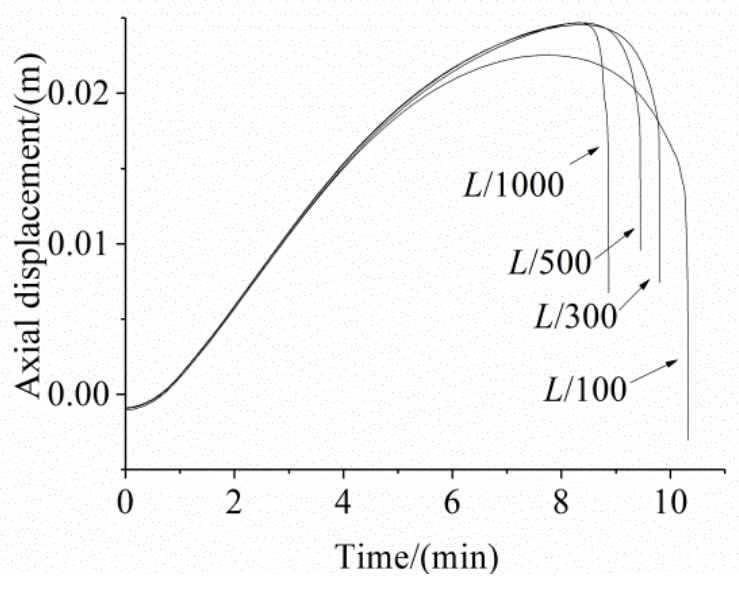

Fig. 10 Load-Displacement curves- $100 \times 100 \times 4$

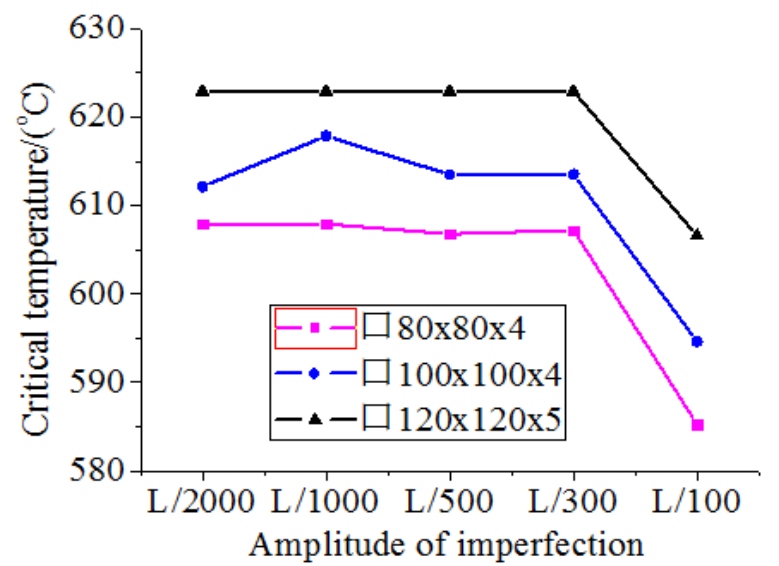

(a) Critical temperature-initial imperfection amplitude curves

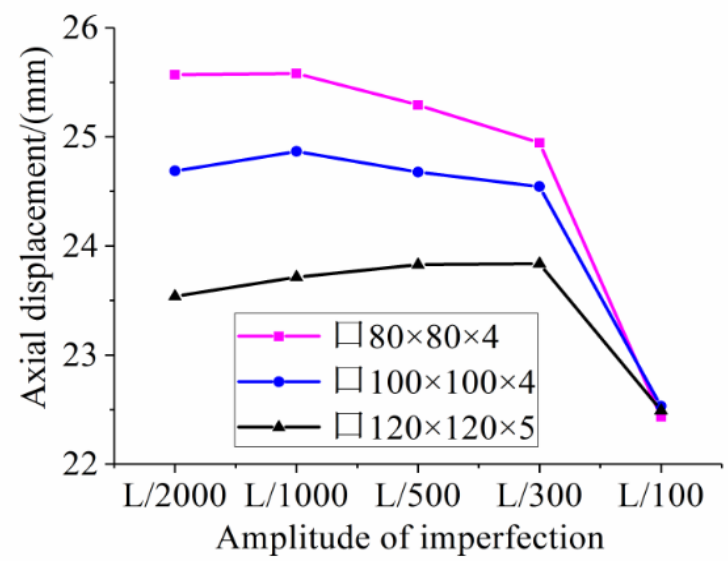

(b) Maximum axial displacement-initial imperfection amplitude curves

Fig. 11 Effects of the initial imperfection amplitude on the

fire resistance of the specimen

Fig. 10 illustrates the axial displacement-time curves of high-strength steel Q550 columns with a square hollow section of $100 \times 100 \times 4$ at different initial imperfection amplitudes. The developing law of this curve is similar to that of curve in Fig. 8.

As shown in Fig. 10, the greater the initial imperfection amplitude is, the better the ductility will be after specimen fail. The axial displacement decreases slowly after the failure of the specimen. Reason for this phenomenon is that the stress state of the specimen is close to the eccentric loading state under large amplitude of initial imperfection amplitude. Ding [34] found that the ductility of an eccentric compression column in fire was better than that of an axial compression column.

As demonstrated in Fig. 11 (a) and (b), the critical temperature and the maximum axial displacement are insensitive to initial imperfection amplitude and only reduces slightly when the initial imperfection amplitude is large (up to $\mathrm{L} / 100$ ). In addition, the increase of the square hollow section improves the critical temperature with limited extent.

\subsection{Slenderness ratio of the specimens}

To have a comprehensive understanding of the effect of the slenderness ratio on the fire resistance of high-strength steel Q550 columns with square hollow section under axial compression, the load ratio and the initial imperfection amplitude maintain the value of 0.3 and $\mathrm{L} / 1000$ respectively. The specimens had various lengths of $2.8 \mathrm{~m}, 3.0 \mathrm{~m}, 3.3 \mathrm{~m}, 3.6 \mathrm{~m}, 3.9 \mathrm{~m}$ and $4.2 \mathrm{~m}$, and the slenderness ratios ranged from 64 to 142. Similarly, only the axial displacement-load curves of the $100 \times 100 \times 4$ specimen are given in Fig. 12 . The maximum axial displacement-critical temperature curves of specimens are provided in Fig. 13 (a) and (b).

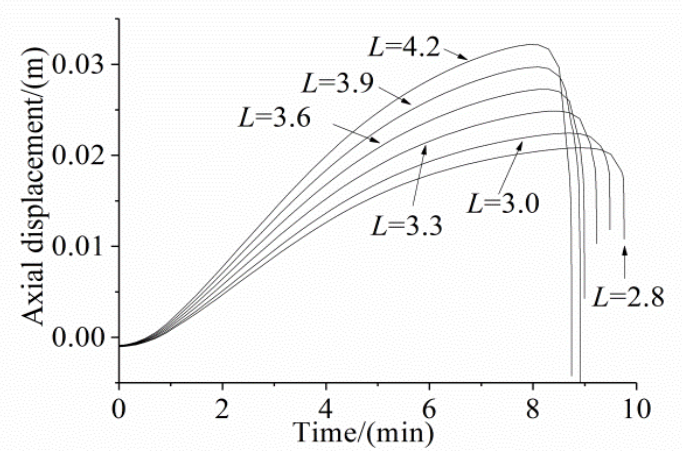

Fig. 12 Load-Displacement curves- $100 \times 100 \times 4$

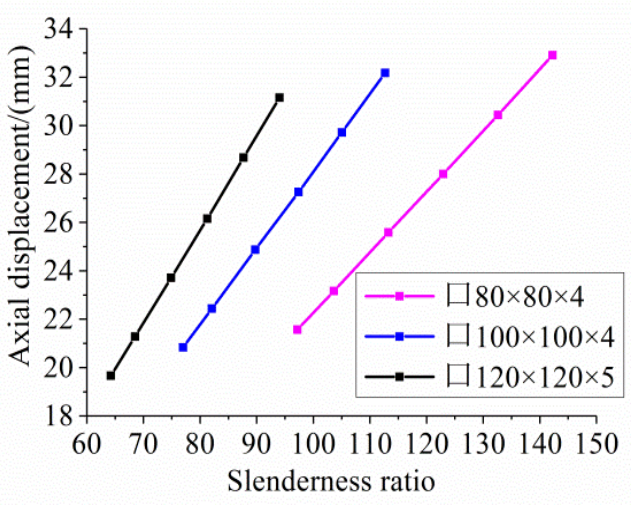

(a) Maximum axial displacement - slenderness ratio curves

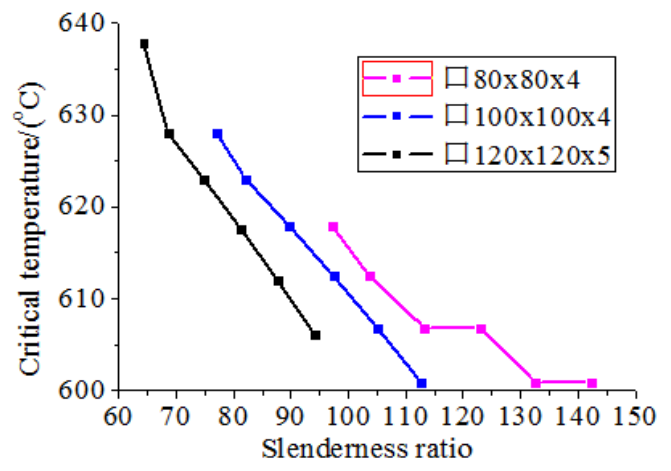

(b) Critical temperature - slenderness ratio curves

Fig. 13 Effects of the slenderness ratio on the fire resistance of the specimen 
Fig. 12 illustrated the axial displacement-time curves of high-strength steel Q550 columns with square hollow section of $100 \times 100 \times 4$ at different lengths with a similar development law with Fig. 8 dividing into three stages. It can be seen from Fig. 13 (a) and (b) that with an increase in specimen length, the maximum axial displacement increases. Simultaneously, the failure time of specimen shortens and the critical temperature reduces. Additionally, the length of specimen has no effect on the ductility after specimen failure, and the axial displacement-time curve drops rapidly after the critical temperature point.

As shown in Fig. 13 (a) and (b), when the slenderness ratio kept constant, the increase of square hollow section of specimens has small reduction on the maximum axial displacement and critical temperature while the slenderness ratio has little effect.

\section{Conclusions}

Based on the domestic high-strength steel Q550 material, the finite element software ABAQUS was adopted to analyze the fire resistance of axially compressed high-strength steel Q550 columns with rectangular hollow section and conclusions are drawn as follows

(1) The proposed high-strength steel column model is capable of simulating the mechanical properties of high-strength steel Q550 columns with square hollow section under axial compression at room and high temperatures.

(2) The load ratio is a major factor affecting the critical temperature of the high-strength steel Q550 columns with rectangular hollow section under axial compression and significantly influences the maximum axial displacement during the fire process.

(3) The initial imperfection amplitude has little impact on the critical temperature and the maximum axial displacement of the high-strength steel Q550 columns with rectangular hollow section under axial compression, but great influence on the mechanical behavior of the steel column after failure. Simultaneously, the greater the initial imperfection amplitude is, the better the ductility of specimen will be after failure.

(4) The slenderness ratio has little effect on the critical temperature of high-strength steel Q550 columns with rectangular hollow section under axial compression.

(5) When the length of steel column keeps constant and the load ratio exceeds 0.6 , the rectangular hollow section size has great influence on the critical temperature of the axially compressed high-strength steel Q550 columns, and the critical temperature of the steel columns can be improved by increasing the rectangular hollow sections.

\section{Acknowledgment}

The authors gratefully acknowledge the financial support of the National Natural Science Foundation of China (No. 51378105 and 51478106). This work is sponsored by the National Key Research and Development Program of China (Grant No. 2017YFC0703802). The research was sponsored by Jiangsu Provincial Qing Lan Project and Jiangsu provincial Six Talent Peaks Project (No. JZ-001). These financial supports are gratefully acknowledge

\section{References}

[1] Shi G., Ban H.Y., Shi Y.J. and Wang Y.Q., "Summary of research progress on steel structure of high-strength steel", Engineering Mechanics, 30(1), 1-13, 2013. (in Chinese)

[2] Fan Z., Liu X.M., Fan X.W., Hu T.B., Wu X.M. and Yu Y.Q., "Design and research of large-span steel structure in national stadium", Journal of Building Structures, 28(2), 1-16, 2007. (in Chinese)

[3] Chen L.R., "The characteristics of structural steel for the main building in new location of China Central Television Station", Steel Structure, 22(91), 1-4, 2007. (in Chinese)

[4] Fu Z.M., "Analysis of fire statistical data in China", Journal of Safety and Environment, 14(6), 341-345, 2014. (in Chinese)
[5] The Fire Department of Ministry of Public Security, China Fire Services, China Personnel Publishing House, Beijing, China, 2013. (in Chinese)

[6] The Fire Department of Ministry of Public Security, China Fire Services, Yunnan People's Publishing House, Kunming, China, 2014. (in Chinese)

[7] The Fire Department of Ministry of Public Security, China Fire Services, Yunnan People's Publishing House, Kunming, China, 2015. (in Chinese)

[8] Url-1. http://china.huanqiu.com/hot/2016-01/8401241.htm.18.01.2016.

[9] Fan S.G., Shu G.P., She G.J. and Liew J.Y. Richard., "Computational method and numerica simulation of temperature field for large-space steel structures in fire", Advanced Steel Construction, 10(2), 151-178, 2014

[10] Fan S.G., Sun W.J., Wei H.Z. and Liu M.J., "Research on the membrane action of profiled steel sheet-concrete composite floors in fire", Advanced Steel Construction, 11(4), 469-491, 2015.

[11] Du Z.L., Liu Y.P. and Chan S.L., "A Second-Order flexibility-based beam-column element with member imperfection", Engineering Structures, 143, 410-426, 2017.

[12] Chinese Technical Code on Fire Safety of Steel Building Structures. (CECS200-2006), Beijing (in Chinese), 2006.

[13] AISC. Load and Resistance Factor Design Specification for Structural Steel Buildings, American Institute of Steel Construction : Chicago, 2005.

[14] EC3. European code 3: Design of Steel Structures-part 1-2: General Rules -Structural Fire Design, British Standards Institution, BS EN 1993-1-2: London, UK, 2005.

[15] Liu B., Wang W.Y., Li G.Q and Dai G.X. "Research on fire resistance of Q460 high-strength steel column", China Civil Engineering Journal, 45(9), 19-26, 2012. (in Chinese)

[16] Shi Z.X., Research on Correlation between Local stability and Overall Stability of Axial Compression Members with The Welded Square Hollow Section of Q550 High-Strength Steel, Doctoral Thesis, School of Civil Engineering, Southeast University, 2015. (in Chinese)

[17] Ban H.Y., Shi G. and Shi Y.J., "Research on overall stability design methods of high-strength steel welded box axial compression members", Journal of Building Structures, 35(5), 57-64, 2014. (in Chinese)

[18] Wang, W.Y., "Fire resistance of high-strength H-beam steel under axial compression", Journal of Chongqing University, 33(10), 76-82, 2010. (in Chinese)

[19] Ge Y., Research on Fire Resistance of Restrained High-strength Q460 Steel Columns, Doctoral Thesis, School of Civil Engineering, Chongqing University, 2012. (in Chinese)

[20] Chen J., Behavior of High Strength Steel Columns at Elevated Temperatures, PhD Thesis, School of Civil Engineering, The University of Hong Kong, 2007.

[21] Qiu L.B., Hou Z.X., Xue S.D., Liu,Y., Chen, S.R., and Qi, Y.L., "Experimental study on axial compression bearing capacity of Q550 high-strength welded H-section steel columns", Progress in Steel Building Structures, 17(3), 7-12, 2015. (in Chinese)

[22] Qiu L.B., Xue S.D., Hou Z.X., Liu Y. and Shu G.P., "Experimental study of residual stresses in Q550GJ high-strength steel welded H-type sections", Journal of Beijing University of Technology, 41(7), 1035-1042, 2015. (in Chinese)

[23] Xue J.Y., Experimental Research on the Overall Buckling Behavior of High-Strength Steel Members under Compression, Doctoral Thesis, School of Civil Engineering, Southeast University, 2014. (in Chinese)

[24] Chen W. and Ye J.H., "Transient state experimental investigation of G550 high-strength cold-formed steel material at elevated temperatures", China Civil Engineering Journal, 45(7), 56-64, 2012. (in Chinese)

[25] Chen W. and Ye J.H., "Steady state experimental investigation of G550 high-strength cold-formed steel material at elevated temperatures", China Civil Engineering Journal, 45(6), 33-42, 2012. (in Chinese)

[26] Liu B., Fire-Resistance Study of High-Strength Steel Columns Subjected to Axial Compression, Doctoral Thesis, School of Civil Engineering, Chongqing University, 2011. (in Chinese)

[27] Schneider R. and Lang J., "Constitutive equations and empirical creep law of structural steel S460 at high temperatures", Journal of Structural Fire Engineering, 2(3), 217-230, 2011.

[28] Chiew S.P., Zhao M.S., and Lee C.K., "Mechanical properties of heat-treated high strength steel under fire/post-fire conditions", Journal of Constructional Steel Research, 98, 12-19, 2014.

[29] Qiang X.H., Jiang X. and Bijlaard F.S.K. and Kolstein H., "Mechanical properties and design recommendations of very high strength steel S960 in fire", Engineering Structures, $112,60-70,2016$

[30] Qiang X.H., Bijlaard F.S. and Kolstein H., "Elevated-temperature mechanical properties of high strength structural steel S460N: experimental study and recommendations for fire-resistance design", Fire Safety Journal, 55, 15-21, 2013.

[31] Ban H.Y., Shi G., Shi Y.J. and Wang Y.Q., "Overall buckling behavior of Q460 high-strength steel welded box section columns under axial compression", Journal of Building Structures, 34(1), 22-29, 2013. (in Chinese)

[32] Shi G., Zhu X. and Ban H.Y., "Material properties and partial factors for resistance of high-strength steels in China", Journal of Constructional Steel Research, 121, 65-79, 2016.

[33] Wang W.Y. and Li G.Q., Fire Safety Design Theory of High-strength Q460 Steel Structures, Science Press, Beijing, China, 2015.

[34] Ding X.F., Experimental Investigation of Axial Compression and Eccentric Compression Stainless Steel Columns at Elevated Temperatures, Doctoral Thesis, School of Civil Engineering, Southeast University, 2013. (in Chinese) 